\title{
Some Reflections on the Meaning, Limits and Challenges of Critical Biographical Research
}

\author{
Fergal Finnegan
}

\begin{abstract}
This chapter offers reflections based on doing critical research using biographical methods for over a decade. It discusses how I formed a identity as a critical researcher within a wider community of research. Drawing on critical theory and critical realism it also outlines a summary of how criticality in research might be understood through a reading of these complementary but distinct traditions. It concludes with some reflections on the limits and value of biographical research in a particular context (an exploration of equality issues and non-traditional student experience in higher education in Ireland).
\end{abstract}

\section{Keywords}

Critical theory - critical realism - biographical methods - equality - reflexivity

\section{Introduction}

The radical adult educator Raymond Williams described keywords as "significant, binding words in certain activities and their interpretation; they are significant, indicative words in certain forms of thought" (1983, p. 15). 'Critical' is a significant and binding word for me and my understanding of the term has strongly informed how I approach my work. It has also been central to how I have puzzled through the challenges of doing biographical research mainly with 'non-traditional' students in higher education (Finnegan et al., 2014, 2019; Fleming et al., 2017) with a particular focus on working class students' experience (Finnegan \& Merrill, 2017). After a decade of doing critical biographical research I want to pause and take the measure of what I have done and learnt.

My aim in writing this chapter is to make sense of "the imperceptible accumulation of the changes that were gradually imposed on me by the experiences

(C) FERGAL FINNEGAN, 2021 DOI: 10.1163/9789004465916_011

This is an open access chapter distributed under the terms of the CC BY-NC 4.0 License. 
of life and that I brought about through work on myself that was inseparable from the work I was doing" (Bourdieu, 2007, p. 68). As such the chapter is at once a personal and a propositional account of how I see research and contains three intertwined strands: biographical reflections on how I developed my approach; a theoretical summary of how I currently understand criticality based on my experience and my reading of critical theory and critical realism; and an assessment of the value and limits of what I have achieved through critical biographical research.

My understanding of what it means to be critical is rooted in a wider field of practice (adult education) and specific networks and groups (most importantly the ESREA Life History and Biographical Network (LHBN) rather than something that was devised or discovered individually. This is perhaps a banal point but nevertheless worth stressing in a period in which an individualistic and competitive conception of research is enthusiastically and widely promoted within neoliberalized universities.

I want to say a little more about this. Before I became an academic researcher, I had been working as an adult education practitioner for just under ten years. Historically, adult education research and pedagogy has been defined by its focus on the collaborative exploration of experience and democratic modes of knowledge creation in support of individual, community and social emancipation. The 'good sense' of the field, elaborated through generations of experiment and collaboration, has become sedimented into practices and ideas which can be more or less taken for granted in many contexts including Ireland. This meant I absorbed a conception of criticality long before I had to articulate it explicitly as an academic researcher. I should say this 'critical habitus' also built on and amended what I had learnt through political activism. As a result, when I began doing biographical research the importance of theorizing power, acting for equality and attempting to create space for people to speak on their own terms was already more or less clear to me. From the outset I was already convinced that we are storied beings and that positivistic approaches to research were alienating and sterile and that despite all the discussion of 'robustness' of 'data collection' methods ignoring lived experience led to trivial and impoverished accounts of the world.

What was far less clear to me was how to conduct academic research in the light of these intuitions and beliefs in an appropriately reflexive way. I was hungry for methodological advice and theoretical resources to develop a more 
nuanced approach to interviewing and analysis. In an important sense I was also searching for some distance from my own assumptions and values. The Life History and Biography Network provided this 'distance' by providing useful advice and ideas which helped me find my feet in my new role as an academic.

Over time LHBN modified the way I saw critical research in several important respects. I became more aware of the embodied aspects of research, the complex way we hear and construct stories and learned to think more carefully about analysis. I can cite texts that were formative (e.g. Alheit, 1994, 2005; Alheit \& Dausien, 200o; West, 1996; Merrill, 2007; Merrill \& West, 2009) but this way of presenting things downplays the relational dimension of this process. Permission to take ownership of ideas, to bridge previous intuitions to new insights, and ultimately to draw on the accumulated history of the network and the wider field of adult education depended on encounters and dialogue with a much wider range of researchers than can be cited here.

The shared commitment to criticality within LHBN as a network has provided me with a much-valued space for elaborating my own particular understanding of critical research. In the next section I want to outline my perspective on this matter and foreground three things in particular: the importance of socio-historical framing, the necessity of working through theory and the centrality of the idea of praxis in critical research. My hope is that by offering a summative and reflexive account of my interpretation on this shared 'keyword' I can spark further debate and discussion in the network and beyond about the various ways we envisage criticality.

Drawing on Diverse Traditions to Theorize Critical Research

\subsection{Critical Theory}

In many respects my approach to biographical research is rooted in critical theory. Critical theory is now a fairly diffuse project but I have in mind a specific rich line of historical materialist inquiry which builds on Marx (1888) and runs from Horkheimer (2002) through to the contemporary work of Honneth (2007) and Fraser (2013) and also underpins the critical pedagogy of Freire (1972) and Apple (2013).

In various ways all these thinkers argue that to understand lived experience in a critical way it requires extensive historical and sociological contextualization combined with an analysis of the sources and distribution of social power. "In any society, in any particular period, there is a central system of practices, meanings and values which we can properly call dominant and effective" (Williams, 2005, p. 38). One of key tasks of critical research is to identify dominant 
interests and values and trace how inequalities in power are linked to unnecessary suffering and harm (Wright, 2010). This type of power analysis therefore also requires a conception of flourishing and justice.

In my experience conceptions of flourishing are often implied rather than stated in critical research. This tendency limits and even forecloses a full discussion about the role of values and politics in research. With that in mind I should briefly say my own perspective is strongly influenced by socialist feminism. Nancy Fraser (2013) has persuasively argued for theory of justice based on greater equality in distribution of goods and resources as well as more egalitarian patterns of social recognition linked to the principle of participatory parity. I am convinced that human flourishing depends on fostering love, care and solidarity (Baker et al., 2009). To achieve this means reimagining how we make and act upon decisions in communities, workplaces and social institutions of all sorts including education.

As the scope of these claims indicates my position differs from a good deal of critical research influenced by postmodernism and post-structuralism. I do not see 'grand-narratives' of collective solidarity and emancipation as necessarily oppressive (Lyotard, 1979) and to my mind critical research which uncovers the ruses of power without any clarity about alternative political and social goals is deeply problematic. Without this the ultimate purpose of critical research is hazy and can easily degenerate into a scholastic performance of criticality. I believe this is rooted in deeper problem - an inability to deal productively with epistemological relativism in research, an issue which I will return to below.

The purpose of this broad framing is to reflect on where and how emancipation is being, or can be, acted upon (Wainwright, 2009; Wright, 2010, inter alia). If the point, as Marx (1888) famously argued, is 'to change things' then criticality requires an orientation to emancipatory praxis which in turn necessitates an analysis of the history and current state of emancipatory social movements as an integral element in the framing of any piece of research.

From my perspective, thorough socio-political analysis, an explicit theory of justice and a clear praxis orientation are fundamental components of critical research and these need to be theorized as a dynamic totality. It is worth noting in this regard that a good deal of critical theory does not do this and is highly scholastic and shows only a faint interest in radical praxis or everyday social practices (Anderson, 1976). Significantly for the present discussion, a great deal of critical theory is 'voiceless'. The terrain of culture and politics is traversed and surveyed but without any sense of the complex ways oppression, inequality and praxis are lived and storied. How people adapt, respond, subvert and resist dominant social logic is often overlooked or assumed to be already understood. This underestimates the importance of emergence which 
is at the heart of the complexities and contradictions of critical biographical research.

These gaps in critical theory reflect wider epistemological problems about what it means to build critical theory through dialogue and the precise role of normative and political commitments in research. Critical theory does not resolve these fully and these issues are addressed far more systematically within critical realism. To return to a point made earlier, critical realists also offer a generative way of understanding epistemological relativism.

\subsection{Critical Realism}

Critical realism (CR) emerged first in the 1970s primarily through the work of the Indian-British philosopher Roy Bhaskar who was studying the history of science and scientific discovery as well as the development of emancipatory knowledge. Over three decades Bhaskar's CR went through several iterations which are quite distinct. My perspective has been mainly influenced by his early work (1979, 2008) what is now termed 'original critical realism' (for a general overview of Bhaskar see Collier, 1994). Bhaskar's work led to the foundation of an International Association for Critical Realism, regular conferences, a book series and the Journal of Critical Realism. This influence has been most significant in the social sciences (for a summary of general methodological implications see Danermark et al., 1997; Sayer, 1992). This includes a network of CR researchers using biographical and life history methods (an edited collection emerged from this see Archer, 2010) and some work dealing with education following Bhaskar's move to the Institute of Education in London (e.g. Barnett, 2013; Scott, 2010 inter alia).

CR offers a distinct way of thinking about the relationship between ontology and epistemology which is rooted in a critique of positivism but frames this differently than hermeneutic, post-structuralist and post-modern thinkers. Put simply CR argues that world exists independently of our descriptions of it and what we know and say does not exhaust or ever fully capture what exists. More formally Bhaskar's (2008) project reasserts the importance of ontology and treats ontology as distinct and irreducible to epistemology. Further, he argues that the world has 'depth' and is stratified and differentiated. He posits the existence of three ontological domains: the empirical, which is the level of phenomenological awareness; the actual, the level of perceived and unperceived events; and the real, the level of activated and unactivated powers. These domains overlap but should not be conflated and part of the work of critical research is to explore patterns of relationship and non-relationship between them. Further, apart from very unusual, tightly controlled circumstances - such as in a laboratory - we should anticipate high levels of 
complexity and emergence due to the unpredictable way various agents, things, events and powers combine.

If we want to comprehend, to pick some examples, the feudal system in England, working class students' experiences in higher education, photosynthesis or the act of lighting a fire we necessarily need to trace the relation between these domains. Being critical depends on seeking explanatory depth by moving from surface descriptions to an analysis of mechanisms, powers and structures. This is true of both natural and social science but according to Bhaskar (1979) the social world differs from the natural world because it is mediated, theory laden and human agents possess specific powers. This has implications for how we understand structure and agency: social structures enable and constrain agency and depend on ongoing intentional and nonintentional actions. Crucially for biographical research, reasons have causal power (Harré \& Secord, 1972) and therefore self-understanding and self-monitoring are fundamental to understand the interplay of structure and agency. We understand very little about the social world if we fail to attend to how people think, feel and act and disregard the highly complex ways this occurs. Open, largely spontaneous accounts of biographical experience are immensely rich, even necessary, resources in tracing how what Archer (2002, 2007) calls "the internal conversation" which shapes patterns of action and emergence within structured contexts.

From a critical realist perspective, the 'flat' ontologies of empiricism and positivism are completely inadequate for thinking about, researching and acting in a complex, layered social world. Identifying correspondences and then ascribing the operation of 'law-like regularities' overlooks both what is specific about human agency and the complexity and depth of social structures. Positivism also misrepresents and obscures what natural science and social science have in common - the search for explanatory depth. These interlinked claims offer a distinct path for thinking about emancipatory social science which is strongly critical of positivism but does not treat natural science and positivism as identical and thus avoids familiar oppositions and dualisms which often hamper critical research (idiographic, particular, subjective versus nomothetic, universal and objective and so forth). This clears the ground for embracing methodological pluralism rather than getting stuck in reified, and reifying, debates about the so-called 'paradigms' of quantitative and qualitative research.

The emphasis realists put on the existence of structures and mechanisms in the social world which typically lie outside, or are at least not prominent, in phenomenological awareness is also significant. If these arguments are correct, they point to the necessity as well as the limits of biographical research for critical social science as a project. This brings us back to the earlier argument about the importance of grasping the socio-historical context in critical research. 
Crucially in terms of contemporary humanities and social science this realist ontology is grounded in epistemic relativism but Bhaskar (1979) argues this does not entail judgmental relativism. While all explanations of feudalism, working class students' experiences in higher education, photosynthesis and fire starting are contingent, fallible and context bound they are not all equally accurate and valuable. Identifying what has appropriate depth and complexity and real explanatory power is certainly contestable, but it is not entirely arbitrary and can be assessed on rational and emancipatory grounds (Bhaskar, 2008). ${ }^{1}$

Critical theory and critical realism argue that attention to the research process needs to be complemented with a clear focus on the social context and goals of critical research. This praxis orientation requires extensive socio-historical framing and a theory of justice which addresses in whose interests, and on what terms, research is being done. Besides this, based on a reading of $\mathrm{CR}$, I have suggested that criticality is linked to being able to identify and work with complexity and emergence and move towards explanatory depth as the research advances.

These are essentially 'framing' remarks. The conduct of field research follows from this but throws up other challenges for critical research. Interviews are embodied, emotional, relational encounters which depend on being present and open to another human being in a meaningful way. This means working through your own fantasies, compulsions and interests on an ongoing basis. This aspect of critical research has a personal dimension and an institutional dimension. As West (1996) points out, drawing on object relations we cannot make sense of the outer world without reflexive exploration of our inner world, and that we need be cognizant of and explore our own biography and positioning to grasp how this influences the joint construction of meaning in research. As Bourdieu (2007) argues, reflexivity also requires a type of sociological imagination; we need concepts and practices which allow us to trace how an embodied intersubjective encounter in an interview is mediated by the field in which it takes place. However distantly and subtly an interview which is undertaken as part of a university research project is marked and influenced by the rituals, structures and struggles of the academic field. I take from this that conducting interviews requires a type of double reflexivity which is attentive to the dynamic intersubjective process of making stories and the way the researcher is situated in social space.

Analysis is a delicate process too, which can easily be flattened into atheoretical and trivial redescription or abstract and disconnected explanation. Criticality for me entails holding on to the integrity of a given story - the 
fullness, complexity and particularity of any individual's life - during thematic and narrative analysis. To do this I ground myself in the stories by listening and relistening to them as well as coding the transcripts. As general themes emerge through analysis, I return to the audio or a clean transcript to connect me to what a particular person said as a whole. Throughout the analysis I try to keep in view the sort of assumptions and experiences I am bringing to the interpretative process mainly by reviewing fieldwork notes and through reflective and biographical writing.

It also follows from the remarks made about the specificities of the social world, including the theory laden nature of social relations and the importance of explanatory depth, that theory is worked through in light of what is learnt through interviews. Using theory to match or 'contain' findings and/or explicitly or tacitly express normative commitments limits or voids criticality. It is on a basic level irrealistic. Criticality therefore depends on making a substantive attempt to rethink concepts through research in the light of an open process of inquiry. The aim is to work through a "double hermeneutic" (Giddens cited in Sayer, 1992) in which everyday and scientific accounts are analyzed in relation to each other and what this then discloses about the structuring of the research context. This entails close attention to how a particular phenomenon is constructed in the scientific field (for example, in my case the various ways social class and inequality have been researched in empirical and theoretical terms). Cultivating what Bourdieu has called "radical doubt" about the adequacy of existing frameworks (Bourdieu \& Wacquant, 1992, p. 235), especially the ones which fit your own initial assumptions, is an important part of deepening the explanatory depth of a piece of research. On a practical level, I have found the selection of a number of 'sensitizing concepts' (Blumer, 1954) a useful way of making sense of the field and your own initial understanding of a phenomenon. Criticality then depends on the recursive movement between interviewees' accounts, ongoing reflection on the research context and questions, and the creative exploration of possible theoretical explanations for what is learnt through this (retroduction). The aim here is to examine the precise way structures and agency interact and identify the powers behind them. This is necessarily iterative but if pursued systematically is a key source of empirical and theoretical discoveries in critical research.

\section{Critical Reflections on the Impact of Praxis Orientated Research}

What has changed as a result of the research? I am fairly certain that deep immersion in biographical stories has altered the shape of my own 'internal conversation' and made it more multi-voiced. As a result, I see my experience 
as a community educator, activist and academic differently. I relate in a new way to my own family stories - especially my father's biography. A number of people whom I interviewed have spoken about the impact and benefits of having space to tell their story and be heard and for these participants it been useful, perhaps transformative in small ways to 'name their world'.

The research has also enhanced the social scientific understanding of education, access and social class in an Irish context. It indicates something about how under-researched these topics are in the Republic of Ireland that this mixed methods research (with biographical research at its heart) is to date the most substantive and sustained body of qualitative research on non-traditional and working-class experience in Irish higher education (Finnegan et al., 2014; Finnegan \& Merrill 2017; Fleming \& Finnegan, 2016; Fleming et al., 2017; Finnegan, 2019; Merrill et al., 2020; O'Neill et al., 2018). In writing reports, articles, books, and doing workshops, and in public advocacy I have tried hard to hold on to the truth of what people said in all its richness and diversity and situate this accurately in the wider socio-political context. I have found when we put life stories at the heart of critical research it shifts the center of gravity in educational discourse in a way that challenges many of the tidy and trim assumptions of policy and 'top-down' research. It has also led to some theoretical innovation in Irish class analysis (specifically in terms of the vital importance of everyday experience and culture in an area of scholarship which has been mainly concerned with either social mobility or political mobilization) and led to the creation of a network of like-minded researchers in other HEIs. This body of work has also had some impact on my institution.

However, my small attempts to use the research to effect changes more widely through discussion with policymakers and employers has had very little effect. Overall, I think I can say the research has explanatory power and has resulted in changes which are not completely insignificant but are fairly modest.

\section{Imposed and Avoidable Constraints: Reflecting on the Rhythms of the Academy}

These modest results did not surprise me as I see academic research as an exercise in 'clearing the ground' and 'praxis orientated' rather than directly emancipatory. Nevertheless, there are things that could be done differently, and I think it is important to be clear about my mistakes and blindspots because I think they disclose something important about power and research. Despite being aware of the structure and demands of the academic field (Bourdieu, 2007), I underestimated the extent to which the logic of this field of practice and its rhythms influenced the way I planned the sequence and prioritisation 
of various tasks and also subtly informed the way I imagined the 'afterlife' of my research. Specifically, while I gave careful attention to power issues in the conduct and analysis and was concerned with how voices were 'heard' in text, I now think I did not plan carefully enough around non-academic modes of engagement and dissemination. I want to draw on Alhadeff-Jones' (2017) very suggestive work on temporalities here and suggest that I have been set, and to an extent have chosen, to adapt to the rhythm of an accelerated university that leaves little time for 'secondary' goals and almost none for unscheduled or unplanned activity. Speaking to students and other researchers and writing for small academic audiences was the main priority and while this was valuable, I now question if I should have spent more time working with social movements and community groups during various research projects as well as exploring other forms of public dissemination besides academic books, articles and presentations. Duckworth and Smith (2017), who have done exemplary work using multiple media platforms alongside academic articles, offer a more clearly praxis orientated strategy of engagement, communication and dissemination. I think the key difference with my own efforts is that they developed a fully integrated dissemination strategy at the outset of their project while I saw this as something that would 'follow' the research once the research was 'mature'.

This rhythm has not only been set by the university. I am very conscious of how funding modalities of external agencies impact, sometimes in quite hidden ways, on research. Michael Rustin (2016) observes that the EU funded sostris project, which used biographical interviews, was critical in intent but foundered somewhat because it was simply too large. The sosTRIS researchers did not conflate 'validity' with scale but nonetheless they took on too many interviews because of the funders' criteria. Most of my research has been funded by the EU and this is how I initially met researchers from LHBN (see Finnegan et al., 2014). We encountered similar problems in relation to the critical analysis of biographical research, in deepening participation with participants and, for me at least, in terms of non-academic engagement and dissemination.

From my perspective the rhythms of the accelerated academy and the demands of funders blunted the critical edge of research. The constraints of university life and funded research cannot be avoided but can be responded to effectively if given some forethought. Yet I think there is a knottier and deeper problem beneath this which deserves consideration. As Bourdieu (2007) never tires of pointing out, distance from practice is both necessary and dangerous. The epistemic breaks which are a precondition of critical research are also a source of alienation. Reflecting on this, I think it is not something that can be really 'solved' individually, rather it takes sustained dialogue within research 
networks on how to link critical research to collective work and social action. The individualized nature of academic research means that unless we explicitly make alliances with groups and movements with emancipatory interests the likelihood is that research will be driven by the traditional expectations and dominant rhythm of the university. ${ }^{2}$

\section{$7 \quad$ In Place of a Conclusion}

Critical research is, by definition, always incomplete, and these reflections are offered in the hope that I can learn from these experiences and perhaps also spark debate within the network and further afield about what critical research means. I have made a case that it involves being personally and politically reflexive, as well as cultivating sensitivity to complexity and emergence. It calls for extensive socio-historical contextualization and consciously seeking explanatory depth. Working through theory and biographical accounts in a recursive way is fundamental for arriving at this depth without overlooking complexity. But it also means exploring what praxis orientated research is and can do. It means knowing how to take distance to see more clearly and critically but also having some sense of how to collaborate with participants, communities and social movements so that research makes a difference.

\section{Notes}

1 Bhaskar's links emancipation, explanatory depth and rationality too tightly together to my mind, but this is complex and cannot be explored in this chapter.

2 In this regard it is worth noting that Duckworth and Smith (2017) were partly funded by a UK Trade Union: the University College Union.

\section{References}

Alhadeff-Jones, M. (2017). Time and the rhythms of emancipatory education. Rethinking the temporal complexity of self and society. Routledge.

Alheit, P. (1994). The "biographical question" as a challenge to adult education. International Review of Education/Internationale Zeitschrift für Erziehungswissenschaft/ Revue internationale l'éducation, 40(3), 283-298.

Alheit, P. (2005). Stories and structures: An essay on historical times, narratives and their hidden impact on adult learning. Studies in the Education of Adults, 37(2), 201-212. 
Alheit, P., \& Dausien, B. (2000). Biographicity as a basic resource of lifelong learning. In P. Alheit, J. Beck, E. Kammler, R. Taylor, \& H. S. Olesen (Eds.), Lifelong learning inside and outside schools: Collected papers of the European conference on lifelong learning (pp. 400-422). Roskilde University.

Anderson, P. (1979). Considerations on western Marxism. Verso.

Apple, M. (2013). Can education change society? Routledge.

Archer, M. S. (2003). Structure, agency and the internal conversation. Cambridge University Press.

Archer, M. S. (2007). Making our way through the world: Human reflexivity and social mobility. Cambridge University Press.

Baker, J., Lynch, K., Cantillon, S., \& Walsh, J. (2009). Equality: From theory to action (2nd ed.). Palgrave Macmillan

Barnett, R. (2013). Imagining the university. Routledge.

Bhaskar, R. (1979). The possibility of naturalism: A philosophical critique of the contemporary human sciences. Humanities Press.

Bhaskar, R. (2008). A realist theory of science. Verso.

Blumer, H. (1954). What is wrong with social theory? American Sociological Review, 18, 3-10.

Bourdieu, P. (2007). Sketch for self-analysis. University of Chicago Press.

Bourdieu, P., \& Wacquant, L. J. D. (1992). An invitation to reflexive sociology. University of Chicago Press.

Collier, A. (1994). Critical realism: An introduction to Roy Bhaskar's philosophy. Verso.

Danermark, B., Ekström, M., Jakobsen, L., \& Karlsson, J. C. (1997). Explaining society: Critical realism in the social sciences. Routledge.

Duckworth, V., \& Smith, R. (2017). Further education in England - Transforming lives and communities: Interim report. UCU.

Finnegan, F. (2019). Opening up the 'Black box': Biographical research on working-class students' experiences and higher education in Ireland. In L. Atkins \& V. Duckworth (Eds.), Research methods for social justice and equity in education (pp. 180-184). Bloomsbury Academic.

Finnegan, F., \& Merrill, B. (2017). 'We're as good as anybody else': A comparative study of working-class university students' experiences in England and Ireland. British Journal of Sociology of Education, 38(3), 307-324. doi:10.108o/01425692.2015.1081054

Finnegan, F., Merrill, B., \& Thunborg, C. (Eds.). (2014). Student voices on inequalities in European higher education: Challenges for policy and practice in a time of change. Routledge.

Fleming, T., \& Finnegan, F. (2014). A critical journey towards lifelong learning: Including non-traditional students in university. In A. Loxley, J. Walsh, \& A. Seery (Eds.), Higher education in Ireland: Practices, policies and possibilities (pp. 146-158). Palgrave Macmillan. 
Fleming, T., Loxley, A., \& Finnegan, F. (2017). Access and participation in Irish higher education. Palgrave.

Fraser, N. (2013). Fortunes of feminism: From state-managed capitalism to neoliberal crisis. Verso.

Freire, P. (1972). Pedagogy of the oppressed. Penguin.

Harré, R., \& Secord, P. F. (1972). The explanation of social behaviour. Blackwell.

Honneth, A. (2007). Disrespect: The normative foundations of critical theory. Polity Press.

Horkheimer, M. (2002). Critical theory: Selected essays. Continuum.

Lyotard, J. F. (1979). The postmodern condition: A report on knowledge. Manchester University Press.

Marx, K. (1888). Theses of Feuerbach.https://www.marxists.org/archive/marx/works/1845/ theses/theses.htm

Merrill, B. (1999). Gender, change and identity: Mature women students in universities. Ashgate Publishing.

Merrill, B., Finnegan, F., O’Neill, J., \& Revers, S. (2020). "When it comes to what employers are looking for, I don't think I'm it for a lot of them': Class and capitals in, and after, higher education. Studies in Higher Education, 45(1), 163-175.

Merrill, B., \& West, L. (2009). Using biographical methods in social research. Sage.

O’Neill, J., Merrill, B., Finnegan, F., \& Revers, S. (2018). Intersecção das desigualdades no ensino superior: teorização de classe e género através de uma perspetiva feminista e o olhar de Bourdieu. In A. Fragoso (Ed.), Estudantes Não-tradicionais no Ensino Superior (pp. 16o-18o). CINEP.

Rustin, M. (2016, March 2-5). What are the objects of biographical and narrative research? Are we really generating resources of hope? Keynote presented at ESREA LHBN Conference Resources of Hope.

Sayer, R. A. (1992). Method in social science: A realist approach (2nd ed.). Routledge.

Scott, D. (2010). Education, epistemology and critical realism. Routledge.

Wainwright, H. (2009). Reclaim the state: Experiments in popular democracy (rev. ed.). Seagull Books.

West, L. (1996). Beyond fragments: Adults, motivation, and higher education: A biographical analysis. Taylor \& Francis.

Williams, R. (1983). Keywords: A vocabulary of culture and society. Oxford University Press.

Williams, R. (2005). Culture and materialism. Verso.

Wright, E. O. (2010). Envisioning real utopias. Verso. 